\title{
Large-scale mutational analysis in the EXT1 and EXT2 genes for Japanese patients with multiple osteochondromas
}

\author{
Daichi Ishimaru1, Masanori Gotoh², Shinichiro Takayama ${ }^{3}$, Rika Kosaki ${ }^{4}$, Yoshihiro Matsumoto ${ }^{5}$, Hisashi Narimatsu², \\ Takashi Sato ${ }^{2}, K_{\text {Koji Kimata }}{ }^{6}$, Haruhiko Akiyama' ${ }^{1}$ Katsuji Shimizu ${ }^{7}$ and Kazu Matsumoto ${ }^{1 *}$
}

\begin{abstract}
Background: Multiple osteochondroma (MO) is an autosomal dominant skeletal disorder characterized by the formation of multiple osteochondromas, and exostosin-1 (EXT1) and exostosin-2 (EXT2) are major causative genes in MO. In this study, we evaluated the genetic backgrounds and mutational patterns in Japanese families with MO.

Results: We evaluated 112 patients in 71 families with MO. Genomic DNA was isolated from peripheral blood leucocytes. The exons and exon/intron junctions of EXT1 and EXT2 were directly sequenced after PCR amplification. Fifty-two mutations in 47 families with MO in either EXT1 or EXT2, and $42.3 \%(22 / 52)$ of mutations were novel mutations. Twenty-nine families (40.8 \%) had mutations in EXT1, and 15 families (21.1\%) had mutations in EXT2. Interestingly, three families (4.2\%) had mutations in both EXT1 and EXT2. Twenty-four families (33.8 \%) did not exhibit mutations in either EXT1 or EXT2. With regard to the types of mutations identified, $59.6 \%$ of mutations were inactivating mutations, and $38.5 \%$ of mutations were missense mutations.

Conclusions: We found that the prevalence of EXT1 mutations was greater than that of EXT2 mutations in Japanese MO families. Additionally, we identified 22 novel EXT1 and EXT2 mutations in this Japanese MO cohort. This study represents the variety of genotype in MO.
\end{abstract}

Keywords: Multiple hereditary exostoses, EXT1, EXT2, Mutational analysis

\section{Background}

Multiple osteochondromas (MO) is a relatively rare autosomal dominant skeletal disorder characterized by the formation of multiple osteochondromas and skeletal deformities, including limb length discrepancy, bowing deformities of the forearms, valgus deformity of the lower extremities, and scoliosis [1-3]. In Western countries, the prevalence of $\mathrm{MO}$ in the general population is one in every 50,000 individuals, and men tend to be affected more frequently than women $[4,5]$. Osteochondroma is a benign bone tumor exhibiting cartilagecapped bone growth that typically originates from the metaphysis of long bones or surface of flat bones. Patients commonly feel pain or irritation of the tissues

\footnotetext{
* Correspondence: mkazuu@gifu-u.ac.jp

${ }^{1}$ Department of Orthopaedic Surgery, Gifu University, Graduate School of Medicine, 1-1, Yanagido, Gifu 501-1194, Japan

Full list of author information is available at the end of the article
}

due to osteochondroma, and some patients may undergo multiple surgeries during their life in an attempt to relieve the symptoms of this disorder [6]. Malignant transformation of osteochondroma toward chondrosarcoma is a serious complication in $\mathrm{MO}$ and occurs in $0.38-7.0 \%$ of patients [6-9].

The exostosin-1 (EXT1) and exostosin-2 (EXT2) genes, which encode heparin sulfate glycosyltransferases, are major causative genes in MO $[10,11]$. EXT1 is located on chromosome 8q23-q24 [12], and EXT2 is located on chromosome 11p11-p12 [13]; these genes are essential for heparan sulfate chain elongation. Approximately $90 \%$ of patients with MO harbor EXT1 or EXT2 germline mutations; however, the genetic background of patients with MO is heterogeneous. Several reports have described mutational variations and novel mutations in EXT1 and EXT2 genes in patients with $\mathrm{MO}$ in several different countries [14-17], and the distribution of 
mutations in the EXT1 and EXT2 genes has been shown to vary. For example, in Spanish patients with MO, $74 \%$ had mutations in EXT1, and $21 \%$ had mutations in EXT2 [14]. In contrast, in Polish patients with MO, 54.6 \% had mutations in EXT1 and $30.3 \%$ had mutations in EXT2 [15]. Most of these mutations are inactivating mutations, including nonsense, frameshift, and splice-site mutations [18]. However, only one study has described variations in genotypes for Japanese patients with MO [16].

Therefore, in this study, we sought to determine genetic backgrounds and mutational patterns in 71 Japanese families with MO; this report describes the genetic diagnostic results of the largest Japanese cohort of MO patients presented to date and identified several novel mutations in the EXT1 and EXT2 genes in MO.

\section{Results}

\section{Identification of 22 novel genetic lesions}

In this study, all exons and intron/exon junctions in EXT1 and EXT2 were sequenced in 112 patients with MO from 71 families. Eighty (71.4\%) patients harbored 52 mutations in either EXT1 or EXT2. All EXT1 and EXT2 mutations are shown in Table 1. Twenty-nine families (40.8\%) had mutations in EXT1, and 15 families $(21.1 \%)$ had mutations in EXT2. Interestingly, three families (4.2\%) had mutations in both EXT1 and EXT2. Twenty-four families (33.8 \%) did not have mutations in EXT1 or EXT2. The distribution of mutations was as follows: $40.4 \%(21 / 52)$ of patients had missense mutations, $30.8 \%(16 / 52)$ of patients had frameshift mutations, $21.2 \%(11 / 52)$ of patients had nonsense mutations, $5.8 \%(3 / 52)$ of patients had splicing mutations, and $1.9 \%(1 / 52)$ of patients had insertions. Of all 52 mutations, 22 mutations $(42.3 \%)$ were novel mutations that had not been registered in the Multiple Osteochondroma Mutation Database (MOdb) (http://medgen.ua.ac.be/ LOVDv.2.0/home.php) [18]. Of these mutations, 17 mutations $(77.3 \%)$ were identified in the EXT1 gene, while five mutations $(22.7 \%)$ were found in the EXT2 gene. The distribution of novel mutations was as follows: $27.3 \%(6 / 22)$ of patients had missense mutations, $31.8 \%$ (7/22) of patients had frameshift mutations, $22.7 \%(5 / 22)$ of patients had nonsense mutations, $9.1 \%(2 / 22)$ of patients had splicing mutations, and $4.5 \%(1 / 22)$ of patients had insertions.

\section{Characteristic genome mutations in five families with MO} Interestingly, five families with $\mathrm{MO}$ showed unique genotypes (MO-11, -25,-44,-47, and -59) as illustrated in Fig. 1. In the family with MO-11, one MO patient harbored missense mutations in both exon 2 of EXT1 and exon 2 of EXT2. Moreover, parents and children in the families with MO-25, -44, and -47 showed different genotypes. In the family with MO-59, a patient had a double missense mutation in EXT1.

\section{Discussion}

In this study, we evaluated the presence and features of EXT1 and EXT2 mutations in Japanese families with MO. Our data demonstrated that 29 families (40.8\%) had mutations in EXT1, and 15 families (21.1\%) had mutations in EXT2. Moreover, three families (4.2\%) had mutations in both EXT1 and EXT2, and 24 families (33.8\%) did not have mutations in either EXT1 or EXT2. Of the 52 mutations observed in this study, 34 mutations were identified in EXT1, and 18 mutations were identified in EXT2. Of the 52 mutations 22 novel mutations were identified. Thus, the data presented herein provides important insights into the genetic causes of MO in Japanese families.

$\mathrm{MO}$ is an autosomal dominant disorder, and germline and heterozygous mutations conferring loss of function in the EXT1 and EXT2 genes are main causes of MO. Mutational variations in EXT1 and EXT2 are continuously being reported; as of January 2015, 432 mutations in EXT1 and 223 mutations in EXT2 were registered in the MOdb (http://medgen.ua.ac.be/LOVDv.2.0/home.php) [18]. Several studies have described the mutational variations in EXT1 and EXT2 in European countries and Asia. For example, in Spanish patients with MO, $74 \%$ were found to have mutations in EXT1, and $21 \%$ were found to have mutations in EXT2 [14]. Additionally, in Polish patients with $\mathrm{MO}, 54.6$ and $30.3 \%$ were found to have mutations in EXT1 and EXT2, respectively [15]. In an Italian cohort, $69 \%$ of patients were found to have mutations in EXT1, and $27 \%$ of patients were found to have mutations in EXT2. In a previous study of Japanese families with $\mathrm{MO}$, 17 (40\%) of the 23 families had a mutation in EXT1, and six (14\%) of the 23 families had a mutation in EXT2 [16]. In contrast, in Chinese families with MO, 13.9 and $33.3 \%$ of the 36 families were found to have mutations in EXT1 and EXT2, respectively [17]. In most studies, the prevalence of EXT1 mutations has been reported to be higher than that of EXT2 mutations. Similarly, in our current analysis, a greater proportion of EXT1 mutations was observed (EXT1: 40.8 \%, EXT2: $21.1 \%$ ). However, mutations in these genes were not identified in 24 families (33.8\%) with $\mathrm{MO}$; this percentage was relatively high compared with that in European countries, where the proportion of patients without mutations in EXT1 and EXT2 has been shown to range from 4 to $24 \%$ (Fig. 2a) [9, 14, 19, 20]. Further studies are needed to examine this finding such as MLPA assays because the families with MO harboring no mutations in this study might include deletion mutation. While the EXT family also includes three EXT-like genes (i.e., EXTL1, EXTL2, and EXTL3) [21-23], no reports have described the presence of gene mutations in these three 
Table 1 Ext1 and Ext2 mutations in Japanese MO families

\begin{tabular}{|c|c|c|c|c|c|c|c|c|}
\hline Familiy number & $\begin{array}{l}\text { The number } \\
\text { of participants }\end{array}$ & Gene & $\begin{array}{l}\text { The number } \\
\text { of the exon }\end{array}$ & Mutation & $\begin{array}{l}\text { Amino acid } \\
\text { change }\end{array}$ & Nucleotide change & $\begin{array}{l}\text { Novel/ } \\
\text { Reported }\end{array}$ & Familial/Sporadic \\
\hline$\overline{\mathrm{MO}-1}$ & 4 & EXT2 & Exon6 & Missense & p.C339F & c.1016G > T & $R$ & $F$ \\
\hline $\mathrm{MO}-2$ & 4 & EXT1 & Exon6 & Frame shift & p.T488fs & c. $1462 \mathrm{~A} \Delta 1 \mathrm{nt}$ & N & $\mathrm{F}$ \\
\hline $\mathrm{MO}-3$ & 3 & EXT1 & Exon6 & Frame shift & p.T490fs & c.1469T $\Delta 1 \mathrm{nt}$ & $\mathrm{R}$ & $\mathrm{F}$ \\
\hline $\mathrm{MO}-4$ & 2 & EXT1 & Exon8 & Frame shift & p.F550fs & 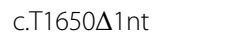 & N & $\mathrm{F}$ \\
\hline MO-5 & 1 & $a_{-}$ & - & - & - & - & - & $\mathrm{F}$ \\
\hline MO-6 & 1 & EXT1 & Exon5 & Frame shift & p.R433fs & C.A1297 $\Delta 2 \mathrm{nt}$ & $R$ & $\mathrm{~F}$ \\
\hline $\mathrm{MO}-7$ & 1 & EXT2 & Exon 5 & Missense & p.R297H & C. $890 \mathrm{G}>\mathrm{A}$ & N & $\mathrm{F}$ \\
\hline MO-8 & 2 & EXT1 & Exon1 & Nonsense & p.Q27X & c. $79 \mathrm{C}>\mathrm{T}$ & $\mathrm{N}$ & $\mathrm{F}$ \\
\hline MO-9 & 2 & - & - & - & - & - & - & $\mathrm{F}$ \\
\hline MO-10 & 1 & - & - & - & - & - & - & $\mathrm{F}$ \\
\hline \multirow[t]{2}{*}{ MO-11 } & 1 & EXT1 & Exon2 & Missense & p.R341S & c. $1023 G>C$ & R & $\mathrm{F}$ \\
\hline & & EXT2 & Exon2 & Missense & p.R128W & c. $382 C>T$ & $\mathrm{R}$ & $\mathrm{F}$ \\
\hline MO-12 & 2 & - & - & - & - & - & - & F \\
\hline MO-13 & 1 & EXT2 & Exon8 & Nonsense & p.W429X & C. $1286 G>A$ & $\mathrm{R}$ & $\mathrm{F}$ \\
\hline MO-14 & 1 & EXT1 & Exon6 & Frame shift & p.L490fs & c.1469T $\Delta 1 \mathrm{nt}$ & $\mathrm{R}$ & $\mathrm{F}$ \\
\hline MO-15 & 1 & - & - & - & - & - & - & $\mathrm{F}$ \\
\hline MO-16 & 1 & EXT2 & Exon3 & Nonsense & p.R182X & c. $544 \mathrm{C}>\mathrm{T}$ & $\mathrm{R}$ & $\mathrm{F}$ \\
\hline MO-17 & 2 & - & - & - & - & - & - & $\mathrm{F}$ \\
\hline MO-18 & 1 & - & - & - & - & - & - & $\mathrm{F}$ \\
\hline MO-19 & 1 & - & - & - & - & - & - & S \\
\hline MO-20 & 1 & EXT2 & Exon5 & Insertion & p.V282ins & c. $846 \mathrm{~A}$ insertion & N & S \\
\hline MO-21 & 2 & EXT1 & Exon2 & Missense & p.R340H & c. $1019 G>A$ & R & $\mathrm{F}$ \\
\hline MO-22 & 1 & - & - & - & - & - & - & $\mathrm{F}$ \\
\hline MO-23 & 2 & - & - & - & - & - & - & $\mathrm{F}$ \\
\hline $\mathrm{MO}-24$ & 1 & EXT2 & Exon5 & Missense & p.R299H & $c .896 G>A$ & R & $\mathrm{F}$ \\
\hline \multirow[t]{2}{*}{ MO-25 } & 1 & EXT1 & Exon5 & Frame shift & p.P466fs & c.1395del del. & R & $\mathrm{F}$ \\
\hline & & EXT1 & Exon8 & Missense & p.F550S & c.1649T > C & $\mathrm{N}$ & $\mathrm{F}$ \\
\hline MO-26 & 2 & - & - & - & - & - & - & $\mathrm{F}$ \\
\hline $\mathrm{MO}-27$ & 1 & EXT2 & Exon2 & Frame shift & p.F30fs & c.88T $\Delta 5 \mathrm{nt}$ & $\mathrm{N}$ & $\mathrm{F}$ \\
\hline MO-28 & 1 & EXT1 & Exon2 & Missense & p.R340L & c.1019G > T & R & $\mathrm{F}$ \\
\hline MO-29 & 2 & EXT1 & Exon3 & Missense & p.C355Y & c. $1064 G>A$ & $\mathrm{~N}$ & $\mathrm{~F}$ \\
\hline MO-30 & 1 & - & - & - & - & - & - & $\mathrm{F}$ \\
\hline MO-31 & 2 & EXT1 & Exon1 & Nonsense & p.W304X & c. $912 \mathrm{G}>\mathrm{A}$ & R & $\mathrm{F}$ \\
\hline MO-32 & 3 & EXT1 & Exon9 & Nonsense & p.W612X & c. $1797 \mathrm{G}>\mathrm{A}$ & R & $\mathrm{F}$ \\
\hline MO-33 & 2 & EXT1 & Exon1 & Frame shift & p.L26fs & c.78 T ( $\Delta 1 \mathrm{nt})$ & N & $\mathrm{F}$ \\
\hline $\mathrm{MO}-34$ & 2 & - & - & - & - & - & - & $\mathrm{F}$ \\
\hline MO-35 & 1 & EXT2 & Intron7 & Splicing mutation & - & c. $(1173+1) G>A$ & $\mathrm{R}$ & $\mathrm{F}$ \\
\hline MO-36 & 1 & EXT2 & Exon3 & Nonsense & p.R182X & c. $544 \mathrm{C}>\mathrm{T}$ & $\mathrm{R}$ & $\mathrm{F}$ \\
\hline MO-37 & 2 & EXT1 & Exon1 & Nonsense & p.Q165X & c.493C > T & $\mathrm{R}$ & $\mathrm{F}$ \\
\hline MO-38 & 1 & - & - & - & - & - & - & $\mathrm{F}$ \\
\hline MO-39 & 1 & - & - & - & - & - & - & $S$ \\
\hline $\mathrm{MO}-40$ & 1 & EXT1 & Exon2 & Missense & p.R340H & c.1019G > A & $\mathrm{R}$ & $\mathrm{F}$ \\
\hline $\mathrm{MO}-41$ & 2 & - & - & - & - & - & - & $\mathrm{F}$ \\
\hline
\end{tabular}


Table 1 Ext1 and Ext2 mutations in Japanese MO families (Continued)

\begin{tabular}{|c|c|c|c|c|c|c|c|c|}
\hline MO-43 & 2 & EXT1 & Exon2 & Missense & p.R341S & c. $1023 G>C$ & $\mathrm{R}$ & $\mathrm{F}$ \\
\hline \multirow[t]{2}{*}{ MO-44 } & 2 & EXT2 & Exon3 & Missense & p.A202V & c. $605 \mathrm{C}>\mathrm{T}$ & $\mathrm{R}$ & $\mathrm{F}$ \\
\hline & & EXT1 & Exon1 & Nonsense & p.G24X & c.70G $>\mathrm{T}$ & $N$ & $\mathrm{~F}$ \\
\hline MO-45 & 4 & EXT1 & Exon1 & Frame shift & p.R314fs & c.941G (+2nt) & $N$ & $\mathrm{~F}$ \\
\hline MO-46 & 1 & EXT1 & Exon1 & Nonsense & p.E74X & $c .220 G>T$ & $N$ & $\mathrm{~F}$ \\
\hline \multirow[t]{2}{*}{ MO-47 } & 1 & EXT2 & Exon2 & Missense & p.L152R & c. $455 \mathrm{~T}>\mathrm{G}$ & $\mathrm{R}$ & $F$ \\
\hline & & EXT1 & Exon1 & Missense & p.Q150R & c. $499 A>G$ & $N$ & $\mathrm{~F}$ \\
\hline MO-48 & 1 & EXT1 & Exon1 & Frame shift & p.T297fs & $c .888 C \Delta 1 \mathrm{nt}$ & $N$ & $\mathrm{~F}$ \\
\hline MO-49 & 4 & - & - & - & - & - & - & $\mathrm{F}$ \\
\hline MO-50 & 2 & EXT2 & Exon7 & Nonsense & p.Y374X & C. $1122 C>A$ & $N$ & $\mathrm{~F}$ \\
\hline MO-51 & 1 & EXT2 & Exon2 & Frame shift & p.S121fs & c.361T $\Delta 2 \mathrm{nt}$ & $\mathrm{R}$ & $\mathrm{F}$ \\
\hline MO-52 & 2 & EXT2 & Exon4 & Missense & p.D227N & c. $679 \mathrm{G}>\mathrm{A}$ & $\mathrm{R}$ & $\mathrm{F}$ \\
\hline MO-53 & 1 & EXT1 & Exon3 & Frame shift & p.M359fs & $\Delta 8 \mathrm{nt}$ & $N$ & $\mathrm{~F}$ \\
\hline MO-54 & 1 & - & - & - & - & - & - & $\mathrm{F}$ \\
\hline MO-55 & 1 & - & - & - & - & - & - & $\mathrm{F}$ \\
\hline MO-56 & 1 & EXT1 & Exon10 & Nonsense & p.Q685X & c. $2053 C>T$ & $\mathrm{R}$ & $F$ \\
\hline MO-57 & 2 & EXT1 & Exon1 & Frame shift & p.K321fs & c. $960 \mathrm{G} \Delta 1 \mathrm{nt}$ & $N$ & $\mathrm{~F}$ \\
\hline MO-58 & 1 & EXT2 & Exon6 & Missense & p.P341T & c. $1021 C>A$ & $N$ & $\mathrm{~F}$ \\
\hline \multirow[t]{2}{*}{ MO-59 } & 1 & EXT1 & Exon1 & Missense & p. $1221 \mathrm{~V}$ & c. $661 A>G$ & $N$ & $\mathrm{~F}$ \\
\hline & & EXT1 & Exon5 & Frame shift & p.P466fs & c. $1395 T \Delta 1 \mathrm{nt}$ & $\mathrm{R}$ & $\mathrm{F}$ \\
\hline MO-60 & 2 & EXT1 & Exon2 & Missense & $\mathrm{p} . \mathrm{R} 340 \mathrm{H}$ & c. $1019 \mathrm{G}>\mathrm{A}$ & $\mathrm{R}$ & $\mathrm{F}$ \\
\hline MO-61 & 2 & EXT1 & Exon1 & Frame shift & p.K218fs & $\Delta 14 \mathrm{nt}$ & $\mathrm{R}$ & $\mathrm{F}$ \\
\hline MO-65 & 1 & - & - & - & - & - & - & $F$ \\
\hline MO-66 & 1 & EXT1 & Exon1 & Frame shift & p.K218fs & $\Delta 18 \mathrm{nt}$ & $\mathrm{R}$ & $\mathrm{F}$ \\
\hline MO-67 & 1 & - & - & - & - & - & - & $S$ \\
\hline MO-68 & 1 & - & - & - & - & - & - & $\mathrm{F}$ \\
\hline MO-70 & 1 & EXT1 & IVS9 & Splicing mutation & & intron/exon10 G > A & $N$ & $\mathrm{~F}$ \\
\hline MO-72 & 2 & EXT1 & Exon1 & Nonsense & p.E139X & $c .415 \mathrm{G}>\mathrm{T}$ & $\mathrm{N}$ & $\mathrm{F}$ \\
\hline MO-73 & 1 & EXT2 & Exon5 & Missense & p.R299H & c. $896 \mathrm{G}>\mathrm{A}$ & $\mathrm{R}$ & $\mathrm{F}$ \\
\hline MO-74 & 3 & - & - & - & - & - & - & $\mathrm{F}$ \\
\hline MO-75 & 2 & EXT2 & Exon4 & Missense & p.D227N & c. $679 \mathrm{G}>\mathrm{A}$ & $\mathrm{R}$ & $\mathrm{F}$ \\
\hline MO-76 & 1 & - & - & - & - & - & - & $\mathrm{F}$ \\
\hline MO-77 & 1 & EXT1 & IVS5 & Splicing mutation & & exon5/intron G > T & $N$ & $\mathrm{~F}$ \\
\hline
\end{tabular}

a - indicates no mutations detected

EXT-like genes in families with MO. Therefore, further studies are needed to determine whether these three genes may be causative genes in families with MO who do not harbor mutations in EXT1 and EXT2 genes.

In $\mathrm{MO}$, the most common mutation types in the EXT1 and EXT2 genes are inactivating mutations, such as frameshift, nonsense, and splice-site mutations [24]. Similarly, in data reported in MOdb from 2009, approximately $80 \%$ of mutations in EXT1 and $77 \%$ of mutations in EXT2 were found to be inactivating mutations (EXT1: frameshift $44 \%$, nonsense $24 \%$, splice-site $11 \%$; EXT2: frameshift $42 \%$, nonsense $22 \%$, splice-site $13 \%$ ) [18]. In Spanish patients with MO, the prevalence of inactivation mutations was reported to be $79.5 \%$ [14]. In our study, 52 mutations were found in EXT1 and EXT2, and $59.6 \%$ (31/ 52 ) of these mutations were inactivating mutations (with $30.8,23.1$, and $5.8 \%$ of mutations being frameshift, nonsense, and splice-site mutations, respectively). The proportion of missense mutation was approximately $38.5 \%$, which was relatively higher in this study than in previous reports (Fig. 2b) [14, 18]. The differences in gene mutations between patients with $\mathrm{MO}$ in Japan and other 
MO-11

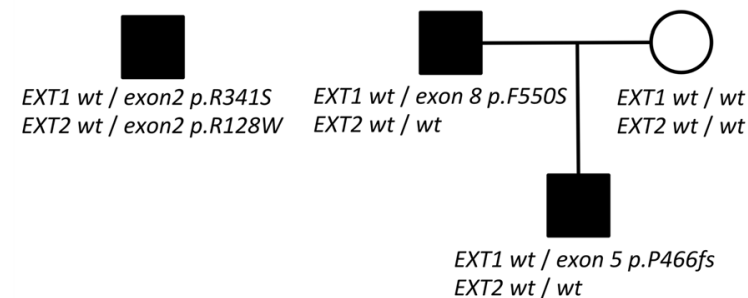

MO-47

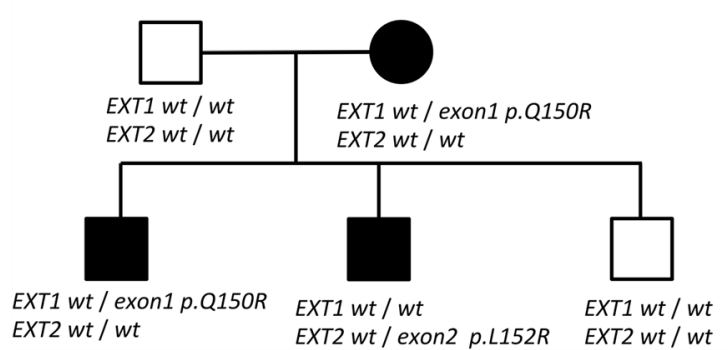

MO-44

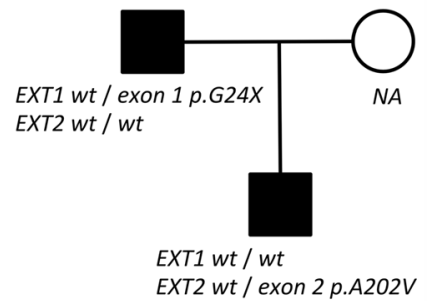

MO-59

EXT1 wt / exon1 p.I221V, exon5 p.P466fs EXT2 wt / wt

Fig. 1 Characteristic mutations and hereditary types in Japanese families with MO. Black mark represents patient with MO. White mark represents healthy person. NA: DNA not available. Written informed consents to publish were obtained from each participants described in this figure before study participation

countries may be related to the differences in the prevalence rates of $\mathrm{MO}$ or the severity of skeletal abnormalities, including scoliosis, in the various countries. Further studies are required to determine the phenotype-genotype relationships in Japanese patients with MO.
In the present study, approximately $7.0 \%(5 / 71)$ of families with MO showed characteristic genotypes, e.g. one patient bearing two mutations and a parent and child bearing different mutations as shown in Fig. 1. Especially, in MO-25, MO-44 and MO-47, there was

\section{a The proportion of EXT1 and EXT2 mutaion}

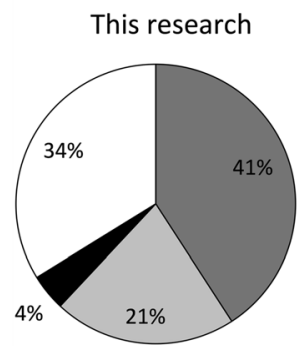

Sarrion et al. 2013

Jamsheer et al. 2014

b The proportion of missense mutation
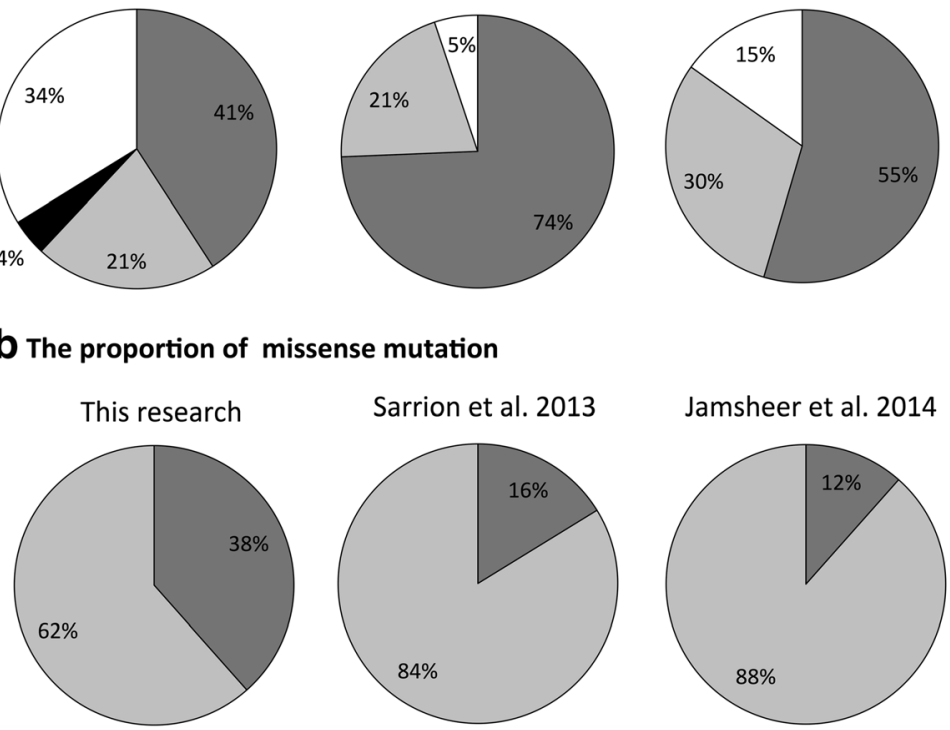

$\square$ EXT1

$\square$ EXT2

- EXT1 EXT2

$\square$ unknown

$\square$ Missense mutation

$\square$ Other

Fig. 2 Comparison of mutation frequencies. a The proportions of EXT1 and EXT2 mutations. $\mathbf{b}$ The proportion of missense mutations 
one affected parent with $\mathrm{MO}$ and one (or two) affected child, but genotypes of child differed from that of the parents. It was reported that approximately $10 \%$ of patients with $\mathrm{MO}$ exhibited de novo mutations [18]; thus, the difference of genotype between parent and child in the three families may be caused by de novo mutations although this scenario may be very unlikely. Therefore, in the future analysis, sequence or genotype might be necessary for the three families to reconfirm these results.

In MO-59, there were two mutations in one MO patient and one was a novel missense mutation. Either mutation might obtain the possibility of it being a nonpathogenic variant; however we evaluated only one genome in MO-59 families, so it is unclear whether mutation is a non-pathogenic variant.

This study has a limitation. In this study, we performed the mutational analysis in EXT1 and EXT2 for Japanese families with MO with using direct sequencing, but MLPA analysis has not been performed for the families with MO harboring no mutations. Thus, the families with $\mathrm{MO}$ harboring gene deletions might not be detected and unknown rate of EXT1and EXT2 mutation potentially are high in this study. Further analysis will be necessary, and now we are planning to perform wholegenome sequencing with using next-generation sequencing technology for the families with MO harboring no mutations. In addition, in MO-25, MO-44 and MO-47, re-sequence or genotype would be performed because of unlikely hereditary form.

\section{Conclusions}

In this study, we evaluated and characterized mutations in the EXT1 and EXT2 genes in 71 Japanese families with MO. A total of 52 mutations in EXT1 and EXT2 were identified, with 22 of these mutations being reported here for the first time. Additionally, we identified several characteristics of gene mutations in EXT1 and EXT2. Approximately $60 \%$ of Japanese families with MO had inactivating mutations in EXT1 and EXT2. Interestingly, these results differed somewhat from those from other countries and represented the variety of genotype in MO. Further studies are needed to determine the reasons for these differences. This study provides important insights into our understanding of the genetic features of $\mathrm{MO}$ in Japanese individuals.

\section{Methods}

\section{Study design and ethical approval}

In this study, we performed a multicenter study at Gifu University, National Center for Child Health and Development, and Kyusyu University. Ethics Committee of Gifu University (Approval No. 22-221) approved all procedures, and all participants obtained written informed consent before any research procedures. In case of the participant under the age of 16 year old, written informed consents (child assent and parental consent) were obtained. In addition, written informed consents to publish were obtained from all patients before study participation, and in the case of the participant under the age of 16 year old, written informed consents to publish (child assent and parental consent) were obtained.

\section{Patients and clinical studies}

From April 2010 to September 2014, patients with MO were recruited for genetic testing of the EXT1 and EXT2 genes. A total of 116 patients (51 women and 65 men) from 74 families with $\mathrm{MO}$ were recruited. Clinical diagnosis was performed based on accurate family histories and physical examinations of the patients, including palpation tests for osteochondromas or joint deformities. Ethics Committee of Gifu University approved all procedures, and all participants obtained written informed consents before all procedures.

\section{Mutation analysis}

Genomic DNA was isolated from peripheral blood leucocytes of all patients with MO using a Wizard Genomic DNA purification kit (Promega, Madison, WI, USA). All exons and exon/intron junctions in the EXT1 and EXT2 genes (GenBank accession numbers NM_000127.2 and NM_207122.1) were amplified by PCR. After confirming amplification of the DNA fragments by agarose gel electrophoresis and purifying the amplified DNA fragments using a Wizard SV gel and PCR Clean-up System (Promega), the amplified DNA fragments were directly sequenced using a BigDye Terminator v1.1Cycle Sequencing kit (ABI). Sequence analyses were then performed with an ABI PRISM 3100 Genetic Analyzer (ABI). Mutations in EXT1 and EXT2 were evaluated by comparing DNA sequences of normal EXT1 and EXT2 genes with the obtained sequences using Sequencher software (Hitachi Software Engineering Co., Ltd., Tokyo, Japan). Primer sequences are shown in Additional file 1: Table S1. The detected mutations in EXT1 and EXT2 were examined to determine whether they had been reported previously by consulting the MOdb (http://medgen.ua.ac.be/LOVDv.2.0/home.php) [18].

In four patients of three families (MO-62, 63, 64), DNA sequence analysis could not be performed because EXT1 and EXT2 genes were not amplified by polymerase chain reaction (PCR). Finally, 112 patients of $71 \mathrm{MO}$ families (48 women and 64 men), DNA sequence analysis was performed. All procedures were approved by Ethics Committee of Gifu University, and all participants obtained written informed consents before all procedures. 


\section{Availability of data and materials}

The Datasets used in this paper can be found at http:// medgen.ua.ac.be/LOVDv.2.0/home.php [18]. All supporting data are included in the manuscript as well as additional files in the supplementary section.

\section{Additional file}

Additional file 1: Table S1. Primer sequences for PCR amplification of the exons and exon/intron junctions of EXT1 and EXT2. (DOCX $21 \mathrm{~kb}$ )

\section{Competing interests}

There are no conflicts of interest to declare, and all the authors certify that they have no commercial associations that might pose a conflict of interest in connection with the study.

\section{Authors' contributions}

DI, acquired data, performed the data analysis, and drafted the manuscript; ST, RK, and YM acquired the data from the patients; MG, HN, and TS performed the data analysis; KM, KK, HA, and KS helped interpret the data and draft the manuscript; KM was involved in the conception and design of the study, analysis and interpretation of the data, and drafting the manuscript. All authors read and approved the final manuscript.

\section{Acknowledgments}

We thank Yu Yamaguchi and Fumitoshi Irue for valuable discussions and useful comments. This study was supported by a Grant-in-Aid for Scientific Research from Ministry of Education, Culture, Sports, Science and Technology of Japan (H22 nanchiippan-209 to K.S.)

\section{Author details}

${ }^{1}$ Department of Orthopaedic Surgery, Gifu University, Graduate School of Medicine, 1-1, Yanagido, Gifu 501-1194, Japan. ${ }^{2}$ Research Center for Medica Glycoscience (RCMG), National Institute of Advanced Industrial Science and Technology (AIST), Tsukuba, Japan. ${ }^{3}$ Department of Orthopedic Surgery, National Research Institute for Child Health and Development, Tokyo, Japan. ${ }^{4}$ Division of Medical Genetics, National Center for Child Health and Development, Tokyo, Japan. ${ }^{5}$ Department of Orthopaedic Surgery, Graduate School of Medical Sciences, Kyushu University, Fukuoka, Japan. ${ }^{6}$ Advanced Medical Research Center, Aichi Medical University, Nagakute, Aichi, Japan. ${ }^{7}$ Spine Center, Gifu Municipal Hospital, Gifu, Japan.

\section{Received: 19 July 2015 Accepted: 1 March 2016}

\section{Published online: 09 March 2016}

\section{References}

1. Akita S, Murase T, Yonenobu K, Shimada K, Masada K, Yoshikawa H. Longterm results of surgery for forearm deformities in patients with multiple cartilaginous exostoses. J Bone Joint Surg Am. 2007;89(9):1993-9.

2. Matsumoto Y, Matsumoto K, Harimaya K, Okada S, Doi T, Iwamoto Y. Scoliosis in patients with multiple hereditary exostoses. Eur Spine J. 2015;24:1568-73.

3. Matsumoto K, Irie F, Mackem S, Yamaguchi Y. A mouse model of chondrocyte-specific somatic mutation reveals a role for Ext1 loss of heterozygosity in multiple hereditary exostoses. Proc Natl Acad Sci U S A. 2010;107(24):10932-7.

4. Schmale GA, Conrad 3rd EU, Raskind WH. The natural history of hereditary multiple exostoses. J Bone Joint Surg Am. 1994;76(7):986-92.

5. Bovee JV. Multiple osteochondromas. Orphanet J Rare Dis. 2008;3:3.

6. Czajka CM, DiCaprio MR. What is the Proportion of Patients With Multiple Hereditary Exostoses Who Undergo Malignant Degeneration? Clin Orthop Relat Res. 2015:473:2355-61.

7. Goud AL, de Lange J, Scholtes VA, Bulstra SK, Ham SJ. Pain, physical and social functioning, and quality of life in individuals with multiple hereditary exostoses in The Netherlands: a national cohort study. J Bone Joint Surg Am. 2012:94(11):1013-20

8. Legeai-Mallet L, Munnich A, Maroteaux P, Le Merrer M. Incomplete penetrance and expressivity skewing in hereditary multiple exostoses. Clin Genet. 1997;52(1):12-6.
9. Pedrini E, Jennes I, Tremosini M, Milanesi A, Mordenti M, Parra A, et al Genotype-phenotype correlation study in 529 patients with multiple hereditary exostoses: identification of "protective" and "risk" factors. J Bone Joint Surg Am. 2011;93(24):2294-302.

10. Ahn J, Ludecke HJ, Lindow S, Horton WA, Lee B, Wagner MJ, Horsthemke B, Wells DE. Cloning of the putative tumour suppressor gene for hereditary multiple exostoses (EXT1). Nat Genet. 1995;11(2):137-43.

11. Stickens D, Clines G, Burbee D, Ramos P, Thomas S, Hogue D, Hecht JT, Lovett M, Evans GA. The EXT2 multiple exostoses gene defines a family of putative tumour suppressor genes. Nat Genet. 1996;14(1):25-32.

12. Ludecke HJ, Ahn J, Lin X, Hill A, Wagner MJ, Schomburg L, Horsthemke B, Wells DE. Genomic organization and promoter structure of the human EXT1 gene. Genomics. 1997:40(2):351-4.

13. Clines GA, Ashley JA, Shah S, Lovett M. The structure of the human multiple exostoses 2 gene and characterization of homologs in mouse and Caenorhabditis elegans. Genome Res. 1997;7(4):359-67.

14. Sarrion P, Sangorrin A, Urreizti R, Delgado A, Artuch R, Martorell L, Armstrong J, Anton J, Torner F, Vilaseca MA, et al. Mutations in the EXT1 and EXT2 genes in Spanish patients with multiple osteochondromas. Sci Rep. 2013:3:1346.

15. Jamsheer A, Socha M, Sowinska-Seidler A, Telega K, Trzeciak T, LatosBielenska A. Mutational screening of EXT1 and EXT2 genes in Polish patients with hereditary multiple exostoses. J Appl Genet. 2014;55(2):183-8.

16. Seki H, Kubota T, Ikegawa S, Haga N, Fujioka F, Ohzeki S, Wakui K, Yoshikawa H, Takaoka K, Fukushima Y. Mutation frequencies of EXT1 and EXT2 in 43 Japanese families with hereditary multiple exostoses. Am J Med Genet. 2001;99(1):59-62.

17. Xu L, Xia J, Jiang H, Zhou J, Li H, Wang D, Pan Q, Long Z, Fan C, Deng HX. Mutation analysis of hereditary multiple exostoses in the Chinese. Hum Genet. 1999;105(1-2):45-50.

18. Jennes I, Pedrini E, Zuntini M, Mordenti M, Balkassmi S, Asteggiano CG, Casey B, Bakker B, Sangiorgi L, Wuyts W. Multiple osteochondromas: mutation update and description of the multiple osteochondromas mutation database (MOdb). Hum Mutat. 2009;30(12):1620-7.

19. Signori E, Massi E, Matera MG, Poscente M, Gravina C, Falcone G, Rosa MA, Rinaldi M, Wuyts W, Seripa D, et al. A combined analytical approach reveals novel EXT1/2 gene mutations in a large cohort of Italian multiple osteochondromas patients. Genes Chromosomes Cancer. 2007:46(5):470-7.

20. Jennes I, Entius MM, Van Hul E, Parra A, Sangiorgi L, Wuyts W. Mutation screening of EXT1 and EXT2 by denaturing high-performance liquid chromatography, direct sequencing analysis, fluorescence in situ hybridization, and a new multiplex ligation-dependent probe amplification probe set in patients with multiple osteochondromas. J Mol Diagn. 2008; 10(1):85-92

21. Van Hul W, Wuyts W, Hendrickx J Speleman F, Wauters J, De Boulle K, Van Roy N, Bossuyt P, Willems PJ. Identification of a third EXT-like gene (EXTL3) belonging to the EXT gene family. Genomics. 1998:47(2):230-7.

22. Wuyts W, Van Hul W, Hendrickx J, Speleman F, Wauters J, De Boulle K, Van Roy N, Van Agtmael T, Bossuyt P, Willems PJ. Identification and characterization of a novel member of the EXT gene family, EXTL2. Eur J Hum Genet. 1997;5(6):382-9.

23. Wise CA, Clines GA, Massa H, Trask BJ, Lovett M. Identification and localization of the gene for EXTL, a third member of the multiple exostoses gene family. Genome Res. 1997;7(1):10-6.

24. Wuyts W, Van Hul W. Molecular basis of multiple exostoses: mutations in the EXT1 and EXT2 genes. Hum Mutat. 2000;15(3):220-7. 